Background Lupus is a complex, heterogeneous disease. We have developed a conceptual model to characterize SLE activity using two dimensions: Type 1 SLE includes active inflammatory manifestations of SLE, including arthritis, nephritis, and rashes; Type 2 SLE includes fatigue, myalgia, mood disturbance, and cognitive dysfunction, which can persist in the absence of inflammatory findings. We have grouped SLE patients into phenotypic clusters based on the extent of Type 1 and 2 SLE features.

Methods Consecutive SLE patients meeting ACR or SLICC criteria in a university rheumatology clinic were included. Patients completed the Systemic Lupus Activity Questionnaire (SLAQ) and the ACR Fibromyalgia (FM) Diagnostic Criteria. The Fibromyalgia Severity Score (FSS) is the sum of the widespread pain (0-19) and symptom severity (0-9) scores. The physicians global assessment (PGA) was also recorded. Patients were grouped into clusters based on PGA (Type I SLE) and FSS (Type 2 SLE) using hierarchical clustering with Wards minimum variance method. Differences were estimated by ANOVA and Fishers exact test.

Results The 419 SLE patients (92\% female; mean age: 45 years) were classified into 7 clusters (figure 1).

Minimal SLE: Clinical Remission $(n=85)$ : minimal Type 1 and 2 SLE.

Clinical Remission with Fatigue $(n=113)$ : minimal Type 1 and mild Type 2 symptoms of fatigue (70\%) and waking unrefreshed $(58 \%)$.

Predominantly Type 1: Moderate Type 1 SLE $(n=56)$ : active Type 1 SLE (43\% arthritis, 55\% anti-dsDNA+) and minimal Type 2 symptoms.

Severe Type 1 SLE $(n=31)$ : severe Type 1 SLE, with active nephritis (39\%), arthritis, new rashes, dsDNA+, and low C3/ C4, with mild Type 2 symptoms, primarily fatigue (61\%).

Predominantly Type 2: Type 2 SLE $(n=58)$ : minimal Type 1 SLE and significant Type 2 symptoms including high widespread pain scores, fatigue (97\%), waking unrefreshed (86\%), depression (67\%), cognitive dysfunction (59\%).

Mixed SLE: Moderate Mixed SLE $(n=52)$ : active Type 1 SLE (69\% arthritis, 35\% anti-dsDNA+) and active Type 2 SLE, with moderate widespread pain scores, fatigue (90\%), waking unrefreshed (96\%), forgetfulness (52\%), and depression (49\%).

Severe Mixed SLE $(n=24)$ : active Type 1 SLE $(54 \%$ arthritis, $25 \%$ proteinuria) combined with severe Type 2 SLE, with high widespread pain scores, depression (86\%), fatigue (100\%), and waking unrefreshed (100\%).

Conclusions Patient-reported measures can be identifying distinct clusters of patients with higher and lower levels of Type 1 and 2 SLE features. We have already found this approach useful in direct clinical care and are working to identify immunologic differences between clusters and optimal management protocols.

Funding Source(s): None

\section{9 COMPARISON OF ACR 1982/1997 AND EULAR/ACR CLASSIFICATION CRITERIA FOR SYSTEMIC LUPUS ERYTHEMATOSUS IN TWO MULTIETHNIC COHORTS}

${ }^{1}$ Guillermo J Pons-Estel ${ }^{*},{ }^{2}$ Manuel F Ugarte-Gil, ${ }^{3}$ Guillermina B Harvey, ${ }^{3}$ Daniel Wojdyla, ${ }^{4}$ Russell Griffin, ${ }^{5}$ Verónica Saurit, ${ }^{6}$ Enrique Soriano, ${ }^{7}$ Eloisa Bonfa, ${ }^{8}$ Loreto Massardo, ${ }^{9}$ Mario H Cardiel, ${ }^{10}$ Luis M Vila, ${ }^{11}$ Graciela S Alarcón, ${ }^{12}$ Bernardo Pons-Estel. 'Grupo Oroño Centro Regional de Enfermedades Autoinmunes y Reumáticas (GO-CREAR); ${ }^{2}$ Universidad Cientifica del Sur, ${ }^{3}$ Facultad de Ciencias Económicas y Estadistica, Universidad Nacional de Rosario, Rosario, Argentina; ${ }^{4}$ Department of Epidemiology, UAB; ${ }^{5}$ Servicio de Reumatología, Hospital Privado Universitario de Córdoba; ${ }^{6}$ Sección de Reumatología, Servicio de Clínica Médica, Instituto Universitario, Hospital Italiano de Buenos Aires; ${ }^{7}$ Rheumatology Division, Faculdade de Medicina, Hospital das Clinicas HCFMUSP, Universidade de São Paulo; ${ }^{8}$ Facultad de Medicina y Ciencia, Universidad San Sebastián; ${ }^{9}$ Centro de Investigación Clínica de Morelia SC; ${ }^{10}$ Division of Rheumatology. University of Puerto Rico; ${ }^{11}$ School of Medicine, The University of Alabama at Birmingham; ${ }^{12}$ Centro Regional del Enfermedades Autoinmunes y Reumáticas (GO-CREAR)

\subsection{6/lupus-2019-Ism.289}

Background Classifying patients as having systemic lupus erythematosus (SLE) is critical for clinical trials and observational studies; although not designed for this purpose, criteria are also frequently used in clinical practice for early diagnosis. The SLICC 2012 criteria are more sensitive but less specific than the 1982/1997 ACR criteria. The refined 2018 EULAR/ ACR criteria differ from the other two sets as they require a positive ANA as the entry point; in addition, the clinical manifestations are clustered into weighted domains with the goal of maximizing the likelihood of an accurate classification of SLE, particularly of early disease.

The objective of the present study was to identify the distinct items of the clinical and immunological domains of the EULAR/ACR SLE classification criteria that differ in the time to criteria fulfillment when compared to the 1982/1997 ACR criteria in two multiethnic lupus cohorts.

Methods Patients from two multiethnic, multicenter cohorts, one from the US and the other from Latin America were included. For these analyses, EULAR/ACR items were evaluated to determine which clinical manifestations and/or laboratory parameters could be of help to achieve an earlier classification of patients. Categorical variables were compared using Chi-square or modified Fisher exact tests, as appropriate. The statistical analyses were performed using SAS software version 9.4.

Results Five-hundred and fifty-eight patients out of 640 from the US cohort and 956 out of 1047 from the Latin America cohort were included. Only $41(7.3 \%)$ and $71(7.4 \%)$ of patients achieved the 2018 EULAR/ACR criteria earlier in the US and Latin American cohorts, respectively. In turn, about one third of the patients in both cohorts achieved them later. Patients who accrued the 2018 EULAR/ACR earlier were more likely to have high anti-dsDNA titers and later earlier classification less likely to have mucocutaneous and joint manifestations; these data are depicted in table 1.

Conclusions When both cohorts were taken it into account, those patients who achieved the 2018 EULAR/ACR criteria 


\begin{tabular}{|c|c|c|c|c|c|}
\hline & $\begin{array}{l}\text { At EULAR/ACR } \\
\text { classification, \% }\end{array}$ & $\begin{array}{c}\text { EULAR/ACR met at } \\
\text { the same time, \% }\end{array}$ & $\begin{array}{l}\text { EULAR/ACR met } \\
\text { earlier, \% }\end{array}$ & $\begin{array}{l}\text { EULAR/ACR met } \\
\text { later, \% }\end{array}$ & $p$ value* \\
\hline ACR/EULAR criteria & $n=558$ & $n=344$ & $n=41$ & $n=173$ & \\
\hline \multicolumn{6}{|l|}{ CLINICAL } \\
\hline Oral ulcers & 30.7 & 25.3 & 0.0 & 48.6 & $<0.0001$ \\
\hline Discoid rash & 9.7 & 8.1 & 0.0 & 15.0 & 0.0027 \\
\hline Malar rash & 45.3 & 38.1 & 14.6 & 67.1 & $<0.0001$ \\
\hline Arthritis & 66.1 & 68.3 & 14.6 & 74.0 & $<0.0001$ \\
\hline Psychosis & 3.1 & 3.2 & 0.0 & 3.5 & 0.7848 \\
\hline Seizures & 5.0 & 6.4 & 2.4 & 2.9 & 0.1821 \\
\hline Pleurisy & 35.8 & 38.7 & 22.0 & 33.5 & 0.0817 \\
\hline Leukopenia & 40.5 & 40.7 & 19.5 & 45.1 & 0.0093 \\
\hline Thrombocytopenia & 12.9 & 14.2 & 12.2 & 10.4 & 0.4736 \\
\hline Autoimmune hemolysis & 7.9 & 7.0 & 19.5 & 6.9 & 0.0307 \\
\hline Proteinuria & 23.5 & 26.5 & 31.7 & 15.6 & 0.0080 \\
\hline Renal biopsy II or V & 8.2 & 8.1 & 26.8 & 4.0 & 0.0001 \\
\hline Renal biopsy III or IV & 4.7 & 4.1 & 9.8 & 4.6 & 0.2405 \\
\hline \multicolumn{6}{|l|}{ IMMUNOLOGIC } \\
\hline $\mathrm{aCL}>40$ & 16.9 & 15.4 & 12.2 & 20.8 & 0.2411 \\
\hline Anti-Smith & 30.3 & 35.8 & 26.8 & 20.2 & 0.0010 \\
\hline Anti-dsDNA & 52.1 & 58.4 & 53.7 & 39.3 & 0.0002 \\
\hline \multicolumn{6}{|c|}{ *By Chi square and Fisher's exact as appropriate } \\
\hline & $\begin{array}{l}\text { At EULAR/ACR } \\
\text { classification, \% }\end{array}$ & $\begin{array}{c}\text { EULAR/ACR met at } \\
\text { the same time, \% }\end{array}$ & $\begin{array}{l}\text { EULAR/ACR met } \\
\text { earlier, } \%\end{array}$ & $\begin{array}{l}\text { EULAR/ACR met } \\
\text { later, \% }\end{array}$ & p value* \\
\hline \multicolumn{6}{|l|}{ ACR/EULAR criteria } \\
\hline CLINICAL & & & & & \\
\hline Fever & 64.6 & 64.4 & 59.2 & 66.3 & 0.515 \\
\hline Oral ulcers & 45.4 & 41.6 & 36.6 & 53.8 & 0.001 \\
\hline Alopecia & 64.9 & 65.7 & 60.6 & 64.4 & 0.687 \\
\hline Subacute cutaneous lupus & 4.3 & 5.0 & 2.8 & 3.3 & 0.397 \\
\hline Discoid lupus & 11.2 & 10.6 & 1.4 & 14.3 & 0.006 \\
\hline Acute cutaneous & 69.0 & 65.5 & 54.9 & 78.1 & $<0.0001$ \\
\hline Synovitis & 84.6 & 83.1 & 78.9 & 88.5 & 0.039 \\
\hline Psychosis & 7.6 & 6.7 & 9.9 & 8.8 & 0.386 \\
\hline Seizures & 10.3 & 10.1 & 8.5 & 10.9 & 0.802 \\
\hline Pleural or pericardial effusion & 31.4 & 30.9 & 26.8 & 33.1 & 0.543 \\
\hline Pericarditis & 16.6 & 16.6 & 16.9 & 16.7 & 0.996 \\
\hline Leucopenia & 56.7 & 55.8 & 53.5 & 59.0 & 0.554 \\
\hline Thrombocytopenia & 24.3 & 24.1 & 25.4 & 24.3 & 0.973 \\
\hline Autoimmune hemolysis & 13.6 & 16.7 & 7.0 & 9.7 & 0.003 \\
\hline Proteinuria & 48.3 & 47.5 & 50.7 & 49.2 & 0.807 \\
\hline Renal biopsy II or V & 7.6 & 6.5 & 8.5 & 9.4 & 0.270 \\
\hline Renal biopsy III or IV & 19.1 & 19.2 & 21.1 & 18.5 & 0.876 \\
\hline \multicolumn{6}{|l|}{ IMMUNOLOGIC } \\
\hline $\begin{array}{l}\text { aCL IgG }>40 \text { GPL or or anti- } \\
\text { B2 microglobulin }>40 \text { or LAC }\end{array}$ & 38.7 & 38.0 & 39.4 & 39.8 & 0.852 \\
\hline $\mathrm{C} 3$ or $\mathrm{C} 4$ & 59.0 & 59.5 & 64.8 & 56.8 & 0.431 \\
\hline $\mathrm{C} 3$ and $\mathrm{C} 4$ & 44.4 & 46.2 & 46.5 & 40.7 & 0.263 \\
\hline Anti-Smith & 26.3 & 26.4 & 22.5 & 26.8 & 0.756 \\
\hline Anti-dsDNA & 67.6 & 68.7 & 77.5 & 63.5 & 0.051 \\
\hline
\end{tabular}

earlier had a lower frequency of milder manifestations (like mucocutaneous and articular) and tend to have a higher frequency of anti-dsDNA antibodies, suggesting these criteria could be more useful in subsets of patients with more severe disease.

Funding Source(s): None

\section{DEVELOPMENT AND FIRST-IN-HUMAN CHARACTERIZATION OF AN ICOSL AND BAFF BISPECIFIC INHIBITOR AMG 570 FOR SLE TREATMENT}

${ }^{1}$ Laurence E Cheng ${ }^{*},{ }^{1}$ Hailing Hsu, ${ }^{2}$ Martin Kankam, ${ }^{3}$ Nicholas Siebers, ${ }^{3}$ Randall Stoltz, ${ }^{1}$ Lubna Abuqayyas, 'Bella Ertik, 'Barbara Sullivan, 'Lei Zhou, 'Jane R Parnes. 'Amgen Inc;

${ }^{2}$ Vince and Associates Clinical Research; ${ }^{3}$ Covance
Background Autoimmune diseases, including systemic lupus erythematosus (SLE), are associated with dysregulated $\mathrm{T}$ cell and B cell responses. AMG 570 is a bispecific molecule targeting $\mathrm{T}$ cell and $\mathrm{B}$ cell activity through inhibition of inducible costimulator ligand (ICOSL) and $\mathrm{B}$ cell activating factor (BAFF). We hypothesize that targeting both ICOSL and BAFF will be more effective than single target inhibition in SLE and other autoimmune diseases. We investigated if targeting ICOSL and BAFF has superior efficacy to single target inhibition in mouse arthritis and lupus models. We also investigated the safety, tolerability, pharmacokinetics, and pharmacodynamics of AMG 570 in healthy subjects after single subcutaneous doses.

Methods A murine surrogate ICOSL/BAFF bispecific along with single or combination inhibition was evaluated in the mouse collagen-induced arthritis (CIA) and NZB/NZW lupus 